\title{
JITTERBUGS E FLÂNEUR: O IDÍLIO MODERNO DO CORPO MÁQUINA
}

Lia Freitas Oliveira

\section{RESUMO}

Theodor W. Adorno e de Walter Benjamin desenvolvem perspectivas que dialogam sobre a técnica e o pensamento reificado da modernidade e as mudanças provocadas no sujeito a partir do advento do capitalismo. Guardando as devidas diferenças, pode-se relacionar a visão de Adorno e Benjamin a partir de duas figuras ilustrativas: jitterbugs e flâneur. Este construído por Benjamin a partir de Baudelaire é a imagem do homem moderno que transita entre as relações fantasmagóricas da mercadoria. O primeiro surge de uma pesquisa sócio-psicológica de Adorno sobre os fanáticos por jazz. O que une estes dois personagens é a estrutura fundamental da lógica do consumo: a máquina.

Palavras-chave: Jitterbugs, flâneur, máquina.

\section{JITTERBUGS AND FLÂNEUR: THE MODERN IDYLL OF THE MACHINE BODY}

\begin{abstract}
Theodor W. Adorno and Walter Benjamin develop perspectives which dialogue on the technical and the reified thought of modernity and the changes caused in the subject from the advent of capitalism. Guarding the necessary differences, we may relate to Adorno's and Benjamin's vision of two illustrative figures: jitterbugs and flâneur. Built by Benjamin from Baudelaire comes the image of the modern man who moves from the ghostly relations of merchandise. The first arises from a sociopsychological research on Adorno's jazz fanatics. The union of these two characters arises from the fundamental structure of the logic of consumption: the machine.
\end{abstract}

Keywords: Jitterbugs, Flâneur, machine.

\section{INTRODUÇÃO}

Em meados do século XIX a reprodutibilidade técnica adquire proporções amplas. O capitalismo ganha força não somente no âmbito da infraestrutura, mas da superestrutura. A partir de tais transformações, cada vez mais a lógica burguesa se imiscui na cultura e passa a ditar novas formas de conduta, de pensamento, de percepção, ou seja, tem ressonâncias diretas na constituição do sujeito. A 
dissolução deste é sintoma mais que comprovado na modernidade. A fragmentação da individualidade, a justaposição de pedaços esvaziados é o que formam essa caricatura chamada homem moderno. Em um artigo sobre música popular, Adorno analisa o desenvolvimento de estandardização da escuta das massas, alertando para o fato de que "o culto da máquina" está presente na batida de todos os grandes sucessos radiofônicos. Isso traz prejuízos à escuta e ao material musical, como causa um mal-estar, reforçado por um comportamento de auto renúncia muito comum aos indivíduos impelidos à adaptação violenta da padronização estereotipada. Adorno exemplifica com os jitterbugs, fãs de jazz fanáticos, que devolvem a repressão sofrida através da histeria e do rancor por seus ídolos. Esse comportamento alimenta a trivialidade dos conteúdos musicais. Assim, a novidade frenética da mercadoria, imiscuindo-se em cada canto, tornou a vida danificada (beschädigtes Leben).

Benjamin encontra caminhos diferentes para a mesma reflexão. Na vivência do choque (Chockerlebnis), corriqueira do homem moderno, citadino, imprime-se em seu corpo a máquina, que se expressa na fuga automática dos choques das cidades. Com a perda da experiência autêntica (Erfahrung) a modernidade tem como consequência a melancolia, o desencanto e o tédio como o ritmo que embala as mentes narcotizadas pela mercadoria. Nesse cenário aparece a figura alegórica do flâneur como ilustração do habitante típico da cidade, envolvido na atmosfera da fantasmagoria e do idílio da novidade mercadológica. Assim, flâneur e jitterbug encontram-se em um frenesi causado pela mercadoria, vivendo a padronização imposta pela máquina, manifestada em seus gestos e escolhas. Os dois filósofos da Teoria Crítica pensam saídas diferentes para esse estado de coisa da modernidade, onde a perspectiva fragmentária será o ponto de partida para novas possibilidades.

Walter Benjamin tem boa parte de sua pesquisa voltada aos acontecimentos e transformações que ocorreram entre o final do século XIX e começo do século XX. O autor analisa o desenvolvimento da reprodutibilidade e do novo modus operandi do homem moderno em muitos de seus ensaios. O mais emblemático a respeito deste assunto é o texto sobre $A$ obra de arte na era de sua reprodutibilidade técnica de 1935/36. Theodor W. Adorno também levanta a mesma questão sobre a modernidade e os impactos desta na subjetividade. A obra escrita em parceria com 
Max Horkheimer, Dialética do Esclarecimento, de 1947, é um panorama crítico de como a razão ocidental se desenvolveu na história, a ponto de culminar no que hoje se entende por lógica capitalista e o pensamento burguês de uma forma geral. Os frankfurtianos trabalharam intensamente nessa concepção crítica da história não só no que se refere à conjuntura política, mas principalmente à cultura e suas reverberações estéticas.

Nesse novo homem que surge no contexto de ofuscamento (Verblendungszusammenhang) - para utilizar um conceito adorniano - envolvido com a reprodutibilidade técnica, se desenvolve também uma outra forma de percepção e comportamento, ditados pelo ritmo da técnica, que tem como signo a máquina. Desde que a máquina se fincou como apêndice do homem, ela não só lhe serviu de instrumento como lhe deu outro corpo, outro olhar, outro modo de operar a reflexão. Sendo assim, é preciso deter-se numa análise estética da subjetividade a partir da visão dos dois autores, onde fenômenos advindos da reprodutibilidade são o cerne do questionamento.

\section{JITTERBUGS E FLÂNEUR, SUJEITOS MODERNOS}

No ensaio sobre a situação da arte em sua era pós aurática, ou seja, a partir do advento da reprodutibilidade técnica, Benjamin salienta as profundas mudanças que a percepção humana passou desde o final do século XIX até a chegada ao ápice da reprodutibilidade no começo do século $X X$. A linguagem cinematográfica inaugura uma nova forma da percepção que vem se desenvolvendo ao longo do século anterior. Todos os avanços que Benjamin comenta no seu ensaio Paris, a capital do século XIX, de 1935/1939, como as construções de ferro, as grandes exposições, a vida cotidiana burguesa, as galerias parisienses são manifestações da massificação e da fantasmagoria que irão culminar no que se vivencia hoje através da experiência estética do homem contemporâneo.

No início do século passado o cinema inaugura uma nova era, a era da imagem. Esta é o signo das massas, ou seja, é na imagem que as massas se identificam e por isso podem se enxergar de maneira mais próxima. A massa procede da mesma forma que a imagem. Ambas se aproximam do mundo captando o semelhante. A imagem, segundo Benjamin, é a expressão plural e panorâmica da realidade, ela deseja captar o instante em seus mínimos detalhes e entregar ao 
espectador a sensação de proximidade, de uma realidade que assalta tão intensamente o olhar que o corpo também se sente absorvido naquele instante. $\mathrm{Da}$ mesma forma a massificação busca aglutinar e aproximar todas as coisas a fim de torná-las semelhantes. Esta lógica é a mesma do fetiche da mercadoria: "Cada dia fica mais irresistível a necessidade de possuir o objeto". ${ }^{1}$

A mercadoria é irresistível porque traz em si o sonho arcaico do Novo, ou seja, o brilho incandescente, a aparência sedutora do objeto de consumo, se comunica com as imagens do inconsciente coletivo, com os arquétipos e utopias que a humanidade construiu como desejo. Assim, a tecnologia ultrapassa o valor de uso e torna-se um ideal utópico, sempre movente, dando voltas em torno do mesmo sonho, mordendo o próprio rabo. Nesse sentido, o homem deseja ardentemente vivenciar esse idílio se assemelhando à inorganicidade do objeto, ${ }^{2}$ pois é como se revestido das couraças metálicas, dos apêndices brilhosos, das coisas mortas, conseguisse alcançar o fantasma que aprendeu a identificar como sendo seu eu.

O indivíduo moderno deseja assemelhar-se aos apêndices que criou: tanto à mercadoria, quanto ao ritmo frenético da máquina. Isso se traduz não só na consciência narcotizada pela fantasmagoria e sua incapacidade de reflexão, mas também no seu corpo contraído. O homem das massas está constantemente aparando os golpes do frenesi maquinário das ruas. Benjamin vai denominar esse treino constante do homem citadino de vivência do choque (Chockerlebnis). Esta é vivida no âmbito da psique, mas também é corpórea. A modernidade trouxe o desenvolvimento tecnológico e com eles veio o surgimento de uma nova forma de lidar com os objetos. A criação do fósforo e o ato brusco necessário para acendê-lo, assim como outros movimentos de apertar, puxar, são exemplos de como a máquina exige do homem uma nova forma de conduta que se adapte à aridez de seus

\footnotetext{
1 Fazer as coisas "ficarem próximas" é uma preocupação tão apaixonada das massas modernas como sua tendência a superar o caráter único de todos os fatos através da sua reprodutibilidade. BENJAMIM, Walter. A obra de arte na era da sua reprodutibilidade técnica. Tradução: Sérgio Paulo Rouanet. São Paulo: Brasiliense, 2008. (Obras Escolhidas: magia e técnica, arte e política), p. 170.

2 Benjamin em seu ensaio $A$ obra de arte na era de sua reprodutibilidade técnica, cita Marinetti quando fala sobre um desejo onírico de metalização do corpo que a estética de guerra proporciona. A guerra é bela porque ela deseja que a massa se identifique com seu aparato técnico de triunfo, porque só pelo simples fato de se enxergar como multidão participante, como a massa que presencia os discursos do ditador, já há uma fruição. A técnica espalha seu brilho arcaico em todo esse processo.
} 
gestos. Benjamin mostra a evolução dessas experiências táteis e o processo de desenvolvimento da vivência do choque:

Com a invenção do fósforo, em meados do século passado, surge uma série de inovações que têm uma coisa em comum: disparar uma série de processos complexos com um simples gesto. (...) Entre os inúmeros gestos de comutar, inserir, etc. especialmente o click do fotógrafo trouxe consigo muitas consequências. Uma pressão do dedo bastava para fixar um acontecimento por tempo ilimitado. O aparelho como que aplicava ao instante um choque póstumo. ${ }^{3}$

Nada na era da máquina é vivido em processo, tudo é um salto, mal se vive o instante e ele já se esvai, como o click rápido de uma máquina. Talvez por isso a emergência da modernidade, com o advento da fotografia, em registrar momentos, como se o homem desejasse lembrar de si mesmo no próprio presente em que vive. A sua figura é sempre tão identificada com algo distante, que ele não é capaz de recordar sobre si e as coisas que vive no presente, porque este não é mais processual, mas se desenrola em um ritmo frenético. Dessa forma, o choque é uma situação permanente na vida moderna. Os golpes que a consciência e o corpo têm de aparar constantemente servem para fixação desses acontecimentos, mecanismo que os indivíduos desenvolvem para manobrar as situações brutais e corriqueiras que surgem na vida hodierna. Os empurrões que tem de driblar na multidão, a buzina do carro, o som estridente da voz de um vendedor na calçada, são exemplos de choques aos quais o indivíduo termina por se acostumar. No que tange ao estudo do surgimento das massas na modernidade, não se pode deixar de falar dos estudos de Benjamin sobre Charles Baudelaire e a flânerie na Paris do século XIX.

Baudelaire carrega a multidão em seus poemas como um véu que apresenta o desvario da modernidade. A figura do flâneur surge da observação baudelairiana desse sujeito que transita entre o burguês completamente absorto pelas relações de produção e o intelectual que tenta se resguardar em seu interior, buscando salvaguardar a individualidade.

Se a galeria é a forma clássica do interior sob o qual a rua se apresenta ao flâneur, então sua forma decadente é a grande loja. Este é, por assim dizer, o derradeiro refúgio do flâneur. Se, no começo, as ruas se transformavam para ele em interiores, agora são esses interiores que se transformam em

${ }^{3}$ BENJAMIN, Walter. Charles Baudelaire: um lírico no auge do capitalismo. Tradução: José Martins Barbosa, Hemerson Alves Baptista. São Paulo: Brasiliense 1989. (Obras Escolhidas III), p. 124.

Lia Freitas Oliveira - Mestranda em Filosofia pela Universidade Estadual do Ceará (UECE). Brasileira, residente em Fortaleza - CE, E-mail: $\underline{\text { liafreitasoliveira@gmail.com }}$ 
ruas, e, através do labirinto das mercadorias, ele vagueia como outrora através do labirinto urbano. ${ }^{4}$

A rua para o flâneur é sua casa. Na verdade, a fantasmagoria das galerias, das ruas, ou da grande loja é onde ele se sente mais à vontade. A fantasmagoria é essencial para a manutenção do seu olhar completamente abandonado na multidão. Ele deseja o inebriar-se nessa relação mítica que a mercadoria provoca: "A última viagem do flâneur. a morte. Seu destino: o novo". ${ }^{5} \mathrm{~A}$ modernidade carrega o caráter ambivalente entre o antigo e o novo. Essa tensão que existe entre os dois polos é o que produz o idílio da mercadoria cuja origem Benjamin encontra no mito. Assim, a novidade mantém o desenvolvimento técnico da produção, ao mesmo tempo em que se utiliza das formas arcaicas das relações sociais. No cerne dessas relações está sempre a mercadoria. O flâneur, neste esforço social que todo indivíduo moderno deve desempenhar para se manter com comodidade no sempre-igual (das Immergleiche), só vê o que deseja ver.

O flâneur é um abandonado na multidão. Com isso, partilha a situação da mercadoria. Não está consciente dessa situação particular, mas nem por isso ela age menos sobre ele. Penetra-o como um narcótico que o indeniza por muitas humilhações. ${ }^{6}$

O indivíduo submerso nas relações sociais burguesas vive numa condição ambivalente entre seguir a marcha social, no impulso da identificação com a mercadoria, e, ao mesmo tempo, em salvar seus resquícios de individualidade, buscando pela novidade ultrapassar as antigas relações. A categoria da novidade é quem provoca esta qualidade ambígua, pois carrega o idílio de que a cada novo desejo criado se podem ultrapassar essas relações sociais arcaicas. No entanto, em verdade, a novidade não é o originalmente novo. É o sempre-mesmo (das Immergleiche), reprodutor do sonho arcaico. Na verdade ela é morte. Dessa forma, o que movimenta as relações de produção é a novidade, trazendo ao indivíduo a necessidade de se identificar com o morto, o objeto inanimado, o inorgânico. Segundo Benjamin:

\footnotetext{
4 BENJAMIN, 1989, p. 51.

5 BENJAMIN, Walter. Paris, capital do século XIX. In: Passagens. Traduções de Irene Aron e Cleonice Paes Barreto Mourão. Belo Horizonte: Editora da UFMG; São Paulo: Imprensa Oficial do Estado de São Paulo, 2009, p. 48.

6 BENJAMIN, 1989, p. 51.
} 
A moda prescreve o ritual segundo qual o fetiche mercadoria deseja ser adorado. (...) Ela se encontra em conflito com o orgânico, unindo o corpo vivo ao mundo inorgânico e fazendo valer no corpo vivo os direitos do cadáver. O fetichismo subjacente ao sex appeal do inorgânico é o seu nervo vital. O culto da mercadoria coloca-o a seu serviço. ${ }^{7}$

O flâneur carrega em seu olhar, em seu desejo as impressões das máquinas. Seu corpo está absorto nesse mundo onde o brilho dos objetos nas grandes lojas e o glamour se encontram. Ele move-se como numa nuvem por entre todos esses choques. Talvez o corpo do flâneur não esteja contraído como o de todos em sua volta, mas seu olhar funciona no mesmo ritmo das engrenagens, na mesma fluidez autômata das esteiras, na cadência incessante da novidade. A realização do seu eu se encontra fora dele mesmo, nas ruas, nos bancos das praças, em cada esquina onde o novo pode lhe assaltar. Este personagem, como já foi falado anteriormente, é uma figura de transição. Só em Paris do século XIX é possível se pensar na flânerie. Quanto mais o capitalismo se desenvolve, mais o corpo é absorvido por seus mecanismos, mais cacoetes são desenvolvidos por este homem caricato. ${ }^{8}$

Assim fica claro como esse desejo pelo objeto tem como consequência a identificação com a máquina. Mas não é um processo consciente, é no inconsciente que essas imagens do desejo são trabalhadas e organicamente se manifestam no corpo e na percepção. Adorno também trabalhou com o conceito de paixão do palpável (Leidenschaft zum antasten), muito próximo ao sex appeal do inorgânico pensado por Benjamin, no qual, segundo ele, todos os indivíduos da sociedade administrada têm a tendência de tocar os objetos da experiência estética segundo seus desejos. Ou seja, o conceito de imanência da obra-de-arte em Adorno, é completamente deixada de lado em favor da padronização estereotipada. Nada pode ser espontâneo e original, mas tudo deve se adequar a visão pré-programada.

Para identificar como acontece esse processo, assim como foi usada a figura do flâneur, será trazido o exemplo dos jitterbugs, fãs americanos extremados de jazz

\footnotetext{
7 BENJAMIN, 2009, p. 45.

8 Aqui pode ser feita uma relação com os filmes de Chaplin, aos quais Benjamin sempre admirou. $O$ longa metragem Tempos Modernos, de 1936, mostra nos movimentos caricatos de Chaplin toda essa vivência do choque falada até aqui. Parece ridículo, por isso cômico, pensarmos na possibilidade dos homens se comportarem daquela forma. Mas com o desenvolvimento técnico, talvez isso se torne algo possível, real. É possível presenciar isso na figura dos jitterbugs tratado mais a diante. Fãs histéricas, gritam, dançam como loucos, se comportam de forma cada vez mais neurótica. Essas são as consequências psíquicas e corpóreas que o desejo de inorganicidade pode levar.
}

Lia Freitas Oliveira - Mestranda em Filosofia pela Universidade Estadual do Ceará (UECE). Brasileira, residente em Fortaleza - CE, E-mail: liafreitasoliveira@gmail.com 
e música popular. Adorno, no escrito Sobre Música Popular de 1941, trabalha o conceito de estandardização da produção musical radiofônica americana. Esse conceito está vinculado a uma avaliação sócio-psicológica desse fenômeno, mas também a uma análise interna da forma musical e de sua formação diante da padronização. Esse processo de estandardização serve para elucidar como acontece a uniformização da mercadoria cultural, tomando a música como exemplo, mas não esquecendo que outras linguagens artísticas (como o cinema) acabam passando por um processo parecido de acordo com suas características. Neste texto o autor usa o exemplo dos jitterbugs para analisar os comportamentos da escuta programada que a indústria cultural criou. Mas além da escuta, há um comportamento corpóreo analisado por Adorno, que é reflexo das dinâmicas sociais e internas sofridas pelos jitterbugs.

Adorno avalia que a estandardização produzida pela indústria cultural provoca nos indivíduos a perda da espontaneidade e da particularidade. Nesse processo os indivíduos se tornam "meros centros de reflexos socialmente condicionados". ${ }^{9}$ Respondem a estímulos de desejos institucionalizados e por isso se tornam incapazes de reflexão, o que significa uma quase que total passividade nos hábitos de escuta do ouvinte de música popular. Ainda assim Adorno vai além e percebe que na mesma tendência à passividade, há uma tendência contrária: "A tendência que transcende os reflexos socialmente condicionados: a tendência à fúria". ${ }^{10}$ Esta é um movimento para autodestruição, que segundo o autor, pode tornar-se incisiva contra os meios de opressão e dissolução do indivíduo.

Esse fenômeno de dissolução do indivíduo ocorre pelo caráter ambivalente da categoria que ele vai denominar de trivialidade. A indústria cultural produz a trivialidade dos conteúdos para que rapidamente sejam substituídos e haja uma constante movimentação mercadológica. Assim, Adorno observa:

\footnotetext{
É essencial à ambivalência que o sujeito não reaja de modo simplesmente passivo. Passividade completa exige uma aceitação inequívoca. No entanto, nem o próprio material, nem a observação dos ouvintes, sustentam a suposição de tal aceitação unilateral. Apenas deixar de resistir não é suficiente para a aceitação do inexorável. ${ }^{1}$
}

\footnotetext{
9 ADORNO, "Sobre Música Popular" in: Theodor W. Adorno: Sociologia. Tradução de Flávio R. Kothe, Aldo Onesti e Amélia Cohn. São Paulo: Editora Ática, 1986, p. 144.

${ }^{10}$ Id. Ibid. 144.

${ }^{11}$ Id. Ibid, p. 144.
}

Lia Freitas Oliveira - Mestranda em Filosofia pela Universidade Estadual do Ceará (UECE). Brasileira, residente em Fortaleza - CE, E-mail: liafreitasoliveira@gmail.com 
Conformar-se, ou ainda, adequar-se, não é um movimento involuntário, mas uma decisão. Assim, a ambivalência do efeito de trivialidade é essencial para a manutenção da novidade de mercado. A ambivalência funciona da seguinte forma: 0 sujeito é convencido de todas as formas que o material que a indústria cultural oferece é o que faltava para completar sua vida. Ela cerca o indivíduo pela propaganda, provocando o desejo incontrolável. Assim, o ouvinte torna-se fã incondicional do hit da vez. Mas ao mesmo tempo, o mecanismo é repetido tantas vezes a cada sucesso novo, que o sujeito sabe, em algum nível de sua psique, que o conteúdo intragável precisa de uma força extra para ser consumido. Assim sendo, utiliza-se da fúria como recurso tanto para o convencimento, como para descartar o mesmo material. Para tanto, eles despendem muita energia libidinal. $O$ fanatismo e a histeria dos jitterbugs é uma decisão voluntária carregada de rancor.

A passividade do comportamento dos jitterbugs é acima de tudo uma decisão, que segundo Adorno, é manipulado pelo ego: "O ego, ao reforçar o entusiasmo "natural" não bastaria para cumprir a tarefa e vencer a resistência. É esse elemento, o de um deliberado forçar, que caracteriza a histeria frenética e consciente de si mesma". ${ }^{12}$ Assim, a decisão não chega às vias da consciência, mas está perto de sua superfície. O convencimento, portanto, tem um caráter duplo, de fora para dentro pela imposição da propaganda, e de dentro para fora pela decisão do sujeito em identificar-se com aquilo que o dissolve.

Os jitterbugs foram nomeados dessa forma por conta de seu comportamento caricato e sua dança espasmódica e sincopada, que mais parece o movimento de insetos incandescidos pelo brilho da luz. Este comportamento provocado pela fúria diz respeito ao movimento maquinal com o qual são condicionados na aceitação, mas também a uma energia que empregam para formar esse corpo, essa autocaricatura, a fim de zombarem de si mesmos, com o objetivo de se sentirem menos culpados com a péssima escolha que fizeram e com sua própria condição. Eles trazem para o próprio corpo a fúria que usam para se submeter ao lixo cultural. Essa aproximação de um corpo maquinal pode estabelecer relação com a ideia da vivência do choque que Benjamin articulou. Os jitterbugs estão constantemente

\footnotetext{
${ }^{12}$ ADORNO, 1986, P. 145.

Lia Freitas Oliveira - Mestranda em Filosofia pela Universidade Estadual do Ceará (UECE). Brasileira, residente em Fortaleza - CE, E-mail: liafreitasoliveira@gmail.com
} 
prontos para aparar os golpes que recebem e devolvem na mesma intensidade através da histeria coletiva.

\section{CONCLUSÃO}

Existe um fascínio que produz o ritmo acelerado e frenético da máquina. $A$ fantasmagoria, ou o fetiche da mercadoria provocam esse corpo espasmódico. É o desejo de se assemelhar ao inorgânico, a paixão por tudo que é palpável. Há uma lógica esquemática, um esqueleto desta rítmica que absorve as individualidades, a espontaneidade, dissolve o sujeito e o transforma em um indivíduo fragmentado, narcotizado, estereotipado. Este não se constitui mais como sujeito consciente, mas em uma encruzilhada de desejos pré-fabricados. A escolha não é mais livre a partir do momento que a consciência está embotada em favor da padronização e a reflexão é sacrificada em favor da produção acelerada.

Independentemente dos prejuízos dessa situação, é indubitável que a forma de interagir do homem, a partir da modernidade, transforma-se intensamente. A tecnologia não é apenas um instrumento, mas uma nova ordem, um novo modo de se portar no mundo. Os olhos, os ombros, as mãos, tudo se move e procede segundo o tempo da máquina. Um novo tempo gera um novo homem e a análise profunda dos dois filósofos tratados aqui chama a atenção para a importância de desenvolver a reflexão a partir de dentro do fenômeno. Um olhar monadológico é a proposta de ambos.

O peso da correnteza é desproporcional ao tamanho do indivíduo. No entanto, Adorno e Benjamin assumem saídas para essa situação, considerando que por maior que seja o esquematismo da lógica burguesa, existem furos onde as individualidades podem rasgar e florescer de maneira potencialmente inovadora e incisiva. Estas perspectivas são extensas, por isso não será abordado no presente trabalho. Fica, portanto, aberta a reflexão de como é formada a subjetividade em tempos modernos. Na verdade é no caráter ambivalente que se pode pensar subterfúgios à regra. 


\section{REFERÊNCIAS}

ADORNO, Theodor W. "Sobre Música Popular" in: Theodor W. Adorno: Sociologia. Tradução de Flávio R. Kothe, Aldo Onesti e Amélia Cohn. São Paulo: Editora Ática, 1986.

BENJAMIM, Walter. A obra de arte na era da sua reprodutibilidade técnica. Tradução de Sérgio Paulo Rouanet. São Paulo: Brasiliense, 2008. (Obras Escolhidas: magia e técnica, arte e política).

. Charles Baudelaire: um lírico no auge do capitalismo. Tradução: José Martins Barbosa, Hemerson Alves Baptista. São Paulo: Brasiliense 1989. (Obras Escolhidas III).

"Paris, capital do século XIX". In: Passagens. Traduções de Irene Aron e Cleonice Paes Barreto Mourão. Belo Horizonte: Editora da UFMG; São Paulo: Imprensa Oficial do Estado de São Paulo, 2009. 